\title{
Role of Patient Conferences in Current Care
}

A cancer survivorship conference can play a central part in survivorship care. The initial concept of patients learning from each other started during World War 1. The injured soldiers drew strength from those around them, learnt from them and motivated themselves to get better. In the same way, with a group of patients, who have been through a similar experience together, can draw strength from each other. A cancer survivorship conference can be held to give a patients' information regarding their condition, give them access to other patients and health care professionals. Armed with this information, patients will then be able to further self- manage themselves.

Cancer Survivorship conferences are held by a range of cancer centres. The MD Anderson Cancer Centre conference included sessions, covering: acute care, body image concerns and oncology and the power of lifestyle change. This forms a core part of survivorship care. In addition the Levine Cancer Centre, USA, gives a strong focus towards patient education, again central to survivorship care. Patient participation conferences have also been held, with the aim of patient empowerment. Conferences have also been held to empower patients about their central role in their own healthcare and to emphasise how patient societies can further their care. This is central to any user-led programme. The British Porphyria Association (BPA) held a patient day included clinical presentations from doctors and patient experience presentations. Patients were able to draw strength from each other. These patient conferences, demonstrate what a difference to patient care can be made [1]. By giving patients knowledge about their condition, and self-empowering themselves, they become their own advocates [2].

\section{References}

1. Ganz PA. Survivorship: adult cancer survivors. Prim Care. 2009;36(4):721-41.

2. Grunfeld E, Earle CC, Stovall E. A framework for cancer survivorship research and translation to policy. Cancer Epidemiol Biomarkers Prev. 2011;20(10):2099-104. 